\title{
Eating Behaviour and Body Satisfaction in Mediterranean Children: the Role of the Parents
}

\author{
Valdo Ricca^, Francesco Rotella^, Edoardo Mannucci”, Claudia Ravaldi^, Giovanni Castellini^, \\ Francesco Lapi $^{\# \#}$, Linda Cangioli ${ }^{\wedge}$, Paolo Martini ${ }^{\# \#}$ and Carlo Faravelli*,o \\ ${ }^{\wedge}$ Psychiatric Unit, Dept. Neuropsychiatric Sciences, Florence University School of Medicine, Viale Morgagni 85, 50134 \\ Firenze, Italy \\ ${ }^{\#}$ Section of Geriatric Cardiology, Department of Cardiovascular Medicine, Florence University School of Medicine, \\ Viale Morgagni 85, 50134 Firenze, Italy \\ ${ }^{\#}$ Department of Preclinical and Clinical Pharmacology, Florence University School of Medicine, Viale Morgagni 85, \\ 50134 Firenze, Italy \\ \#\#\# Mental Health Service Arezzo, Via Guido Monaco 13, Arezzo, Italy \\ Department of Psychology, Florence University, Via San Niccolò, 93, 50125, Firenze, Italy
}

\begin{abstract}
Although the prevalence of fully expressed Eating Disorders is rare in young children, childhood eating disturbances are fairly common. Parents can play a facilitating role for the development of overweight and eating problems among their children. The aim of this study is to detect the possible relationships between children's eating attitudes and behaviour and the parents' beliefs about eating habits and body shape of their offspring.

This survey was conducted in the area of Arezzo (Italy), on 900 children, aged 7-12, and on their parents/substitute caregivers. The Kids' Eating Disorder Survey questionnaire, and the CIBUS questionnaire were administered.

A fully expressed Eating Disorder was diagnosed in two kids only. KEDS total score and weight/dissatisfaction subscale score positively correlated with parents' answers to the following CIBUS' items (How do you consider the body shape of your son/daughter? How much does your son/daughter eats? Have you ever thought of putting your son/daughter on a diet?). Positive correlations between the children BMI, desired BMI and the aforementioned CIBUS' items were found.

The prevalence of formal Eating Disorders in children aged 7-12 is low. Children appear to be more preoccupied with their weight than with their body shape. Parents' beliefs about the offspring's body shape and eating habits have a relevant impact on children's eating attitudes and behaviour.
\end{abstract}

Key Words: Body shape, body weight, childhood, parents eating behaviour.

\section{INTRODUCTION}

Overweight and Eating Disorders (EDs) are a relevant health problem in Western countries, and their incidence and prevalence in juvenile populations have remarkably increased in the last decades $[1,2,3,4]$.

Although the prevalence of fully expressed Anorexia Nervosa (AN) and Bulimia Nervosa (BN) is as low as $1 \%$ in children and young adolescents, AN can occur from the age of 8 , whereas $\mathrm{BN}$ is very rare under $12[5,6,7]$. On the other hand, even if full blown EDs are rare in young children, both weight and body shape concerns and eating disturbances seem to be fairly common [8]. In school-based studies of 813 year-old children, a relevant proportion of subjects report dieting and exercising to lose weight; furthermore, a high Body Mass Index (BMI) is associated with size dissatisfac-

*Address correspondence to this author at the Department of Psychology, Florence University, Via San Niccolò, 93, 50125, Firenze, Italy; Tel: +39 55 6236047; Fax: +39 55 6237811; E-mail: carlo.faravelli@unifi.it tion and attempts to lose weight [9-11]. In particular, young girls show body dissatisfaction to a greater extent than boys, as suggested by several studies [12-15]. Studies on overweight and obese children highlighted EDs symptoms, such as loss of control over eating, dieting, shape and weight concerns and drive for thinness, which could lead to the development of a full syndrome in adolescence or adulthood [16, 17]. These observations suggest that EDs in children may be present with unusual features, so that they often do not fit neatly within a formal psychiatric diagnostic category. According to a recent study, children suffering from EDs are often diagnosed with Eating Disorders not otherwise specified (EDnos), and are less likely to engage in purging behaviours compared with adolescents [18].

It is well known that the prevention of psychiatric disorders depends on the identification of modifiable causal risk factors. Familial environment can play an important role, facilitating the onset of eating and/or weight disturbances in children $[19,20]$. The role of parental beliefs about eating behaviours of their offspring has been investigated as a po- 
tentially modifiable risk factor [19-22]. In particular, food restriction has been found to be associated with disinhibition in presence of palatable foods, even after a full meal [23-25], and parents' encouragement of weight control seem to be related to the children's dieting and desire to be thinner [26]. Perceived weight-related pressure and mother's body shame could influence the development of disordered eating patterns, and parents may influence the development of body image by commenting on children's appearance, or by requiring the child to eat or avoid certain foods, or by encouraging him/her to slim down $[27,28]$. Moreover, parental modelling of weight concerns may contribute to body esteem problems in children, and parents' comments about the body of their children seem to be related to the offspring's body satisfaction [29-34].

This study is aimed at evaluating eating attitudes and behaviour, body image, and body dissatisfaction in a population of 7-12 year-old children. Furthermore, the parents' beliefs and concerns about the body and the weight of their children were evaluated, in order to detect possible relationships between the children's and parents' variables taken into account. In particular, the study was designed to explore the effect of parents' beliefs on body shape and eating habits of their offspring on the childrens' eating attitudes.

\section{MATERIALS AND METHODOLOGY}

\section{Sample and Study Design}

This study was conducted in the town of Arezzo (Tuscany-Italy) and its immediate surroundings. The whole population of this area is about 105,000 inhabitants. The study sample consisted of two groups: a group of 900 children aged 7-12, attending Primary or Secondary school, and the group of their parents or substitutive caregivers. The study design was approved by the Arezzo Health Authority Ethical Board and a permission from the authorities of each school to conduct the study was obtained. Informed consent was obtained from the parents prior to enrolment.

The children were recruited from 10 Primary (two third classes, two forth classes and two fifth classes) and Secondary (two first classes and two second classes) schools of the centre and the immediate surroundings of Arezzo. Schools were selected through a randomized geographic sampling process, in order to obtain a representative sample of the different socio-cultural contexts (urban centre, suburban areas, rural areas) of the area of Arezzo. At the beginning of the study, teachers and parents received a personal letter from the principal investigator (V.R.), inviting them to participate to the study and to attend a meeting, which took place in each school, where they were provided with information about the study aims and procedures. The fact that anonimity was warranted, and that partecipation was voluntary, was also clearly stated during those meetings.

\section{Instruments}

In order to assess the presence/absence of symptoms of disordered eating and possible eating disorders, all children were administered the Italian validated version [35] of the Kids' Eating Disorder Survey (KEDS) [36]. The test is reliable and useful in identifying children with EDs as determined by clinical interview, and it was shown to have excel- lent test-retest validity and reliability as well as good internal consistency in prepubertal children. The range of score for all items is $0-2$, and there are 12 items. A score of 0 means that the behaviour is not present, 1 means that it is possibly present, 2 means it is definitely present. The test provides weight dissatisfaction and purging restriction subscales (KWD and KPR, respectively), as well as a total score. Two sample items of KEDS are as follows: "Have you ever thought that you looked fat to other people?"; "Have you ever been afraid to eat because you thought you would gain weight?". Two of the items do not load on either the weight dissatisfaction or purging/restriction scales but are included in the total KEDS score [37]. Elevated responses to the total KEDS score are defined as scores greater than 16 . In order to evaluate the body size dissatisfaction, subjects were asked to indicate their current and desired size using drawings on the KEDS' child figures. Body size dissatisfaction score was calculated as the difference between current and desired size. A greater absolute value of the score indicates more dissatisfaction with current body size.

All the parents or substitutive caregivers were administered the CIBUS self-reported questionnaire [38]. This questionnaire is composed of 34 items, and is devoted to the investigation of parents' thoughts and beliefs about their own and their children's eating behaviours and body shape. It also includes some questions investigating age, educational level, height (meters), and weight (kilograms).

In the present study, only the responses to the items of CIBUS listed in the Appendix were considered.

\section{Procedures}

Children were given the KEDS questionnaire by teachers in their classrooms during school hours. Teachers were invited to avoid to explain questions or suggest answers, so that children were as less influenced as possible. Children were invited to mark questions they couldn't answer with a question mark. Teachers collected the completed questionnaires and marked them with a letter corresponding to the one signed on parent's test, so that each family nucleus could be recognized, while anonymity of all participants was warranted.

Subsequently, the CIBUS Questionnaire was provided to the students, who delivered it to their parents. Each child brought home two copies of the questionnaire for parents or substitutive caregivers, and each parent filled in the selfreport form on his/her own. Tests were completed during the week-end and collected from school teachers on the subsequent Monday.

\section{Body Mass Index}

For each child BMI was calculated on the basis of height (meters) and weight (kilograms), as provided by their general practitioner. Data obtain from the KEDS' item "desired weight" was used to calculate the desired BMI for each subject.

\section{Statistical Analysis}

Statistical analysis was performed by means of the Statistical Package for Social Sciences (SPSS) for Windows (release 15.0.0; SPSS, Inc.). 
Table 1. Anthropometric and Clinical Features of the Children

\begin{tabular}{|c|c|c|c|}
\hline & $\begin{array}{c}\text { Overall } \\
\mathbf{n = 7 6 9}\end{array}$ & $\begin{array}{c}\text { Male } \\
\mathbf{n = 3 6 3}(\mathbf{4 7 . 2 \%})\end{array}$ & $\begin{array}{c}\text { Female } \\
\mathbf{n = 4 0 6}(\mathbf{5 2 . 8 \%})\end{array}$ \\
\hline \hline Sig.* & & $10(9-11)$ & 0.054 \\
\hline Age (yrs) & & $10(9-11)$ & $145(138-152)$ \\
\hline Height (cm) & $145(138-151)$ & $143(138-150)$ & $36(30-42)$ \\
\hline Weight (kg) & $36(31-42)$ & $36(31-42)$ & 0.42 \\
\hline real BMI & $17.8(16-19.8)$ & $17.6(16-19.9)$ & 0.892 \\
\hline desired BMI & $16.8(15.2-18.3)$ & $17.2(15.5-18.9)$ & $16.4(15.1-17.8)$ \\
\hline KEDS & & & 0.004 \\
\hline Total score & $4(1-7)$ & $3(1-7)$ & $4(1-7)$ \\
\hline Body dissatisfaction subscale & $0(0-1)$ & $2(0-6)$ & 0.71 \\
\hline Purging/restriction subscale & $0(0-1)$ & 0.039 \\
\hline
\end{tabular}

Statistics - Data are expressed as median value (with $25^{\text {th }}$ and $75^{\text {th }}$ percentiles). (*): Male to female comparison using Mann-Whitney U Test. Abbreviations - Keds: Kids' Eating Disorder Survey.

Table 2. Characteristics of the Parents

\begin{tabular}{|c|c|c|}
\hline & Mothers & Fathers \\
\hline \hline Age & $39(36-42)$ & $42[38-45)$ \\
\hline Weight $(\mathrm{Kgs})$ & $58(54-65)$ & $79[72-85)$ \\
\hline Height (Meters) & $1.64(1.60-1.68)$ & $25.1(23.6-27.1)$ \\
\hline BMI $\left(\mathrm{Kg} / \mathrm{m}^{2}\right)$ & $21.7(20.2-24.1)$ & $44.1 \%$ \\
\hline Educational level & & $43.5 \%$ \\
Primary School & $38 \%$ & $12.4 \%$ \\
\hline
\end{tabular}

Statistics - Data are expressed as median value (with $25^{\text {th }}$ and $75^{\text {th }}$ percentiles). Abbreviations- BMI: Body Mass Index.

The values of normally distributed variables were expressed as mean $\pm \mathrm{SD}$, whereas the values of skewed variables were expressed as median values [quartiles]. Spearman's correlation analyses, chi-square testing, and independent variables Mann-Witney U tests were performed when appropriate. Multiple linear regression was used for multivariate analysis.

Considering the large number of analyses, in order to limit type 1 error, significance level was set at $<0.01$.

\section{RESULTS}

Of the 900 children invited, $19(2,1 \%)$ did not receive consent from their parents. Among the participating children, $784(89 \%)$ returned the questionnaires to the teachers. Fifteen of these could not be analysed, because more than $20 \%$ of answers were missing. Of the remaining 769 subjects, 36 were excluded because parents' questionnaires had not been completed. The final sample was therefore composed of 733 children, with their parents/substitute caregivers.
Age, Height, Weight, BMI and desired BMI, KEDS total and subscales scores are summarised in Table $\mathbf{1}$, whereas the parents' data collected through the CIBUS questionnaire are reported in Table 2.

Only two kids scored higher than 16 on KEDS total score. Desired BMI, KEDS body dissatisfaction and Purging/Restriction subscales showed a statistically significant difference between males and females. The same variables were considered to compare kids living in urban areas with kids living in rural areas, in order to detect possible differences between the two socio-economical environments. No differences were found for age, height, weight, actual and desired BMI (data not shown). When considering KEDS scores, only the Purging/Restriction subscale scores were found to be significantly higher in kids living in urban areas $([0 ; 1]$ vs $[0 ; 0] ; \mathrm{p}<0.001$ for males and $[0 ; 1]$ vs $[0 ; 0]$; $\mathrm{p}=0.007$ for females).

The percent difference between real and desired BMI (BMId) was $0[-5 ;+15] \%$ and $8[0 ;+15] \%$ in males and fe- 
Table 3. KEDS Correlations After Adjusting for Children's Age and BMI

\begin{tabular}{|c|c|c|c|c|c|c|}
\hline & \multicolumn{3}{|c|}{ Females } & \multicolumn{3}{|c|}{ Males } \\
\hline & Keds $\mathbf{T}$ & KPR & KWD & Keds T & KPR & KWD \\
\hline Breakfast with son/daughter (Father) & n.s. & n.s & n.s. & n.s. & n.s & n.s. \\
\hline Thoughts about child's body shape (Father) & n.s. & n.s & n.s. & $.18^{*}$ & n.s & n.s. \\
\hline $\begin{array}{l}\text { Thoughts about child's body shape } \\
\text { (Mother) }\end{array}$ & $.18^{*}$ & n.s. & $.21 *$ & $.17^{*}$ & n.s. & $.17 *$ \\
\hline Child's weight importance (Mother) & n.s. & n.s & n.s. & n.s. & n.s & n.s. \\
\hline How much child eats (Father) & n.s & n.s & n.s. & n.s. & n.s & n.s. \\
\hline How much child eats (Mother) & n.s. & n.s & n.s. & $.26^{*}$ & n.s. & $.29 *$ \\
\hline $\begin{array}{l}\text { Ever thought about a diet for the child } \\
\text { (Father) }\end{array}$ & $.27 *$ & n.s. & $.26^{*}$ & $.26^{*}$ & n.s. & $.25^{*}$ \\
\hline $\begin{array}{l}\text { Ever thought about a diet for the child } \\
\text { (Mother) }\end{array}$ & $.33 *$ & n.s. & $.34 *$ & $.23^{*}$ & n.s. & $.21^{*}$ \\
\hline
\end{tabular}

Statistics - Multiple linear regression; * $\mathrm{p}<0.01$

Abbreviations - KPR=Keds purging/restriction subscale; KWD= Keds weight dissatisfaction subscale; BMI: Body Mass Index; BMId: Body Mass Index desired.

males, respectively $(\mathrm{p}=0.001)$. For both genders, no significant correlation between age and KEDS scores or BMId was observed.

KEDS total scores showed a significant $(\mathrm{p}<0.01)$ correlation with children's BMI in both sexes ( $r=0.48$ and 0.38 in females and males, respectively), whereas KWD was correlated with BMI in females only $(r=0.51)$. KPR showed a significant $(\mathrm{p}<0.01)$ inverse correlation with children's age both in females $(r=-0.29)$ and males $(r=-0.35)$. In females only, KEDS total and KWD scores were positively correlated with children's and both parents' BMI $(r=0.32$ and $r=$ 0.31 respectively for fathers; and $r=0.25$ and $r=0.25$ for mothers). Correlation of KEDS total score, KWD, and KPR with other variables collected from KEDS and CIBUS questionnaires, after adjustment for age and BMI, are summarised in Table 3. In females, the frequency with which the father usually has breakfast with his daughter had a negative correlation with KEDS total score, but this result was not confirmed after adjusting for age and BMI; however mothers' Item 2 (Thoughts about child's body shape) and both fathers' and mothers' Item 5 (Thoughts of putting child on a diet) maintained their positive correlation with KEDS total score at multivariate analysis. In males, KEDS total score significantly correlated with mothers' Items 2, 4 (How much child eats) and 5 and fathers' Items 2 and 5. KWD, in males, maintained a positive correlation after adjusting for age and BMI, with mothers' Items 2 and 4 and both fathers' and mothers' Item 5; in females, the same correlations were confirmed, except for mothers' Item 4.

Children's BMId showed a positive correlation with children's $(p<0.001)$ and parents' actual BMI $(p<0.001$ for mothers' and $\mathrm{p}=0.01$ for fathers'), as with KEDS total and KWD scores $(\mathrm{p}<0.001)$ in both sexes, and with KPR scores $(p=0.001)$ in females only. The results of correlations between BMI and BMId with CIBUS, after adjusting for age and BMI, are summarized in Table 4. BMId showed a significant correlation with mothers' Item 2 and fathers' Item 4 and both fathers' and mothers' Item 5 in females, and only with fathers' and mothers' Item 4, in males.

\section{DISCUSSION}

Few studies have considered eating attitudes and behaviour and body dissatisfaction in a population sample of children living in a Mediterranean country [39, 40]. The present data confirm that, in this area, the prevalence of fully expressed EDs is low, as suggested by the small number of subjects with a KEDS score greater than 16. Despite the relatively low prevalence of relevant disturbances of eating attitudes and behaviour, many children reported a desired body weight considerably lower than their actual weight; this phenomenon was more pronounced in females and, as expected, in overweight children. The difference between desired and actual body weight positively correlated with KEDS total and weight dissatisfaction scores, and the abnormal eating attitudes appear to be more frequent in females than in males. In particular, young girls tend to show a lower desired weight and a greater body dissatisfaction than boys, as already observed [13-15].

Parents' perception of children's body shape and eating habits appear to have a relevant impact on children's eating attitudes and behaviour, as explored by KEDS. Some Authors reported that mothers have a primary role for female attitudes toward dieting and body weight and shape [40-43]. This result, however, could be influenced by the fact that full $\mathrm{AN}$ or $\mathrm{BN}$ are investigated and diagnosed mainly in mothers of children with disordered eating attitudes $[44,45]$. On the other hand, Leung [46] and Agras [12], showed that parental (both father's and mother's) body and weight preoccupation and pressure to be thin may influence child's BMI, thus considering parental control as an independent risk factor for EDs. Our results confirm these previous observations, as significant correlations were found for both parents. In particular, those schoolchildren who are perceived by their parents as overeaters have higher mean KEDS total and sub- 
Table 4. BMId Correlations with CIBUS Items after Adjusting for Age and BMI

\begin{tabular}{|c|c|c|}
\hline \multirow{2}{*}{} & \multicolumn{2}{|c|}{ BMId } \\
\cline { 2 - 3 } & Females & Males \\
\hline \hline Thoughts about child's body shape (Father) & n.s. & n.s. \\
\hline Thoughts about child's body shape (Mother) & $.15^{*}$ & n.s. \\
\hline Importance of child's weight (Father) & n.s. & n.s. \\
\hline Importance of child's weight (Mother) & n.s. & $.19^{*}$ \\
\hline How much child eats (Father) & $.14^{*}$ & $.27^{*}$ \\
\hline How much child eats (Mother) & n.s. & n.s. \\
\hline Ever thought about a diet for the child (Father) & $.15^{*}$ & n.s. \\
\hline Ever thought about a diet for the child (Mother) & $.17^{*}$ & \\
\hline
\end{tabular}

Statistics - Multiple linear regression: $* \mathrm{p}<0.01$.

Abbreviations - BMI: Body Mass Index; BMId: Body Mass Index desired.

scale scores, and a greater difference between actual and desired weight, irrespective of their BMI. Not surprisingly, parents' thoughts of putting their children on a diet are associated with higher KEDS scores in children. Similarly, the recurrent parents' thoughts about children's body shape seem to affect children's eating attitudes and desired BMI. On the other hand, parents' preoccupations about children's weight do not appear to moderate those variables in a relevant manner, after adjusting for real BMI. These results suggest that children's body shape, rather than their actual weight, could be the main parents' drive for their children's thinness, whereas children appear to be more preoccupied with their weight, rather than to their body shape.

Considering the possible protective factors, having breakfast with parents, and in particular with the father, negatively correlates with ED symptoms, as observed in a recent study [19], although this correlation lost its statistical significance after adjusting for children's age and actual BMI.

Overall, although it is very difficult to define factors which modulate the transmission between generations of beliefs and behaviours related to eating and body shape, our results confirm that parents' eating attitudes are connected with eating behaviours of their children. Although some Authors pointed out that the mechanisms for the intergenerational transmission of these behaviours have yet to be established [47], some studies found that girls' body dissatisfaction, purging behaviours and drive for thinness are related to higher levels of family history of eating concerns [18], and that the mother's drive for thinness is one of the predictors of the development of EDs in offspring [48].

This study presents some limitations:

1) The assessment of the general psychological and psychopathological features of the children and parents was not performed. Therefore, we were unable to detect some possible meaningful correlations between eating and weight problems, and children mental status. For the same reason, the possible correlations between the children's eating and weight abnormalities, and the parents' psychopathological features were not studied. Furthermore, self-reported questionnaires were administered by the teachers, instead of trained psychologists. Although the latter could represent a limitation, this procedure ensured that results of the tests were not affected by opinions or diagnostic attempts of health professionals.

2) In order to calculate the children's BMI, we used the height and weight measures as provided by their general practitioner, possibly determining some bias.

3) Menarchal status was not assessed in females. However, it should be considered that neither KEDS scores nor desired weight were significantly correlated with age, although the proportion of post-menarchal females can be assumed to increase progressively with age.

4) The CIBUS questionnarire is an instrument developed in Italian language, and it has never been translated and validated in othger languages; this makes the results difficult to reproduce in different countries. However, the relationship between parents' beliefs and children's eating attitudes is likely to be affected by cultural determinants, which interfere with the generalizability of results.

5) Although response rates were very high, some cases were missing because either the children or their parents refused participation. It is possible that those declining participation had different psychological and cultural characteristics and/or eating habits than those enrolled in the study.

\section{CONCLUSION}

Our study suggests that the prevalence of full-blown Eating Disorders is low, and that many children are dissatisfied with their body weight. The parents' beliefs about the body shape and the eating habits of the children seem to have a relevant impact on their eating attitudes and behaviour. Larger, prospective studies are needed in order to clarify the possible causal role of parents in the development of overweight and eating disorders in their children. 


\section{Appendix 1. Items of CIBUS Used for Analysis}

Item 1: How many times a week do you have the main meals with your son/daughter?

a) Breakfast $01 / 23 / 45 / 67$

b) Lunch $01 / 23 / 45 / 67$

c) Dinner 0 1/23/45/67

Item 2: How do you consider the body shape of your son/daughter?

a) Thin

b) Well-proportioned

c) Fat

d) I don't know

Item 3: How important to you is your son/daughter's weight?

a) Not important

b) A little important

c) Very important

d) 1 don't know

Item 4: According to you, your son/daughter eats:

a) Too little

b) Enough

c) Too much

d) I don't know

Item 5: Have you ever thought of putting your son/daughter on a diet?

a) No, never

b) Yes, but I didn't do it

c) Yes,I have my son/daughter on a diet that I run by myself

d) Yes, I took him/her to a dietician

\section{REFERENCES}

[1] Cecil-Karb R, Grogan-Kaylor A. Childhood body mass index in community context: neighborhood safety, television viewing, and growth trajectories of BMI. Health Soc Work 2009; 34: 169-77.

[2] Hedley AA, Ogden CL, Johnson CL, Carroll MD, Curtin LR, Flegal KM. Prevalence of overweight and obesity among US children, adolescents, and adults, 1999-2002. JAMA 2004; 291: 2847-50.

[3] Matthiessen J, Velsing Groth M, Fagt S, et al. Prevalence and trends in overweight and obesity among children and adolescents in Denmark. Scand J Public Health 2008; 36: 153-60.

[4] Nicholls D, Viner R. Eating disorders and weight problems. BMJ 2005; 330: 950-3

[5] Bravender T, Bryant-Waugh R, Herzog D, et al. Workgroup for Classification of Eating Disorders in Children and Adolescents (WCEDCA). Classification of child and adolescent eating disturbances. Int J Eat Disord 2007; 40: 117-22.

[6] Bryant-Waugh R, Lask B. Eating disorders in children. J Child Psychol Psychiatry 1995; 36: 191-202.

[7] Lask B Bryant-Waugh R. Early onset anorexia nervosa and related eating disorders. J Child Psychol Psychiatry 1992; 33: 281-300.

[8] Phares V, Steinberg AR, Thompson JK. Gender Differences in Peer and Parental Influences: Body Image Disturbance, Self-Worth, and Psychological Functioning in Preadolescent Children. J Youth Adolesc 2004; 33: 421-9.

[9] Maloney MJ McGuire J, Daniels SR, Specker B. Dieting behaviour and eating attitudes in children. Pediatrics 1989; 84: 482-9.

[10] McVey G, Tweed S, Blackmore E. Dieting among preadolescent and adolescent females. Can Med Assoc J 2004; 170: 1559-61.

[11] Mirza NM, Davis D, Yanovski JA. Body dissatisfaction, selfesteem, and overweight among inner-city Hispanic children and adolescents. J Adolesc Health 2005; 36: 16-20.

[12] Agras WS, Bryson S, Hammer LD, Kraemer HC. Childhood risk factors for thin body preoccupation and social pressure to be thin. J Am Acad Child Adolesc Psychiatry 2007; 46: 171-8.

[13] Collins ME. Body figure perceptions and preferences among preadolescent children. Int J Eat Disord 1991; 10: 199-208.

[14] Cusumano DL and Thompson JK. Media influence and body image in 8-11 year-old boys and girls: A preliminary report on the Multidimensional Media Influence Scale. Int J Eat Disord 2001; 29: 3744.
[15] Williamson S and Delin C. Young children's figural selections: Accuracy of reporting and body size dissatisfaction. Int J Eat Disord 2001; 29: 80-4.

[16] Lundstedt G, Edlund B, Engstrom I, Thurfjell B, Marcus C. Eating disorder traits in obese children and adolescents. Eat Weight Disord 2006; 11: 45-50.

[17] Tanofsky-Kraff M, Faden D, Yanovski SZ, Wilfley DE, Yanovski JA. The perceived onset of dieting and loss of control eating behaviors in overweight children. Int J Eat Disord 2005; 38: 112-22.

[18] Peebles R Wilson JL, Lock JD. How do children with eating disorders differ from adolescents with eating disorders at initial evaluation? J Adolescent Health 2006; 39: 800-5.

[19] Benninghoven D, Tetsch N, Kunzendorf, S, Jantschek G. Body image in patients with eating disorders and their mothers, and the role of family functioning. Compr Psychiatry 2007; 48: 118-23.

[20] Faith MS, Scanlon KS, Birch LL, Francis LA, Sherry B. Parentchild feeding strategies and their relationships to child eating and weight status. Obes Res 2004; 12: 1711-22.

[21] Faith MS, Berkowitz RI, Stallings VA, Kerns J, Storey M, Stunkard AJ. Parental feeding attitudes and styles and child body mass index: Prospective analysis of a gene-environment interaction. Pediatrics 2004; 114: 429-36

[22] Heitzler CD Martin SL, Duke J, Huhman M. Correlates of physical activity in a national sample of children aged 9-13 years. Prev Med 2006; 42: 254-60.

[23] Carper JL, Orlet Fisher J, Birch LL. Young girls' emerging dietary restraint and disinhibition are related to parental control in child feeding. Appetite 2000; 35: 121-9.

[24] Faith MS. Development and modification of child food preferences and eating patterns: behaviour genetic strategies. Int J Obes 2005; 29: 549-56.

[25] Fisher JO, Birch LL. Restricting access to a palatable food affects children's behavioral response, food selection, and intake. Am J Clin Nut 1999; 69: 1264-72.

[26] Moreno AB, Thelen MH. Eating behavior in junior high school females. Adolesc Spring 1995; 30: 171-4.

[27] McKinley NM. Women and objectified body consciousness: mothers' and daughters' body experience in cultural, developmental, and familial context. Dev Psychol 1999; 35: 760-9.

[28] Ricciardelli LA, McCabe MP, Banfield S. Body image and body change methods in adolescent boys. Role of parents, friends and the media. J Psychosom Res 2000; 49: 189-97.

[29] Jacobi C, Schmitz G, Agras WS. Interactions between disturbed eating and weight in children and their mothers. J Dev Behav Pediatr 2008; 29: 360-6.

[30] Keery H, Boutelle K, Van den Berg P, Thompson JK. The impact of appearance-related teasing by family members. J Adolesc Health 2005; 37: 120-127.

[31] Ricciardelli LA, McCabe MP. Children body image concerns and eating disturbance: a review of the literature. Clin Psychol Rev 2001; $21: 325-344$

[32] Schwartz DJ, Phares V, Tantleff-Dunn S, and Thomson JK. Body image, psychological functioning and parental feedback regarding physical appearance. Int J Eat Disord 1999; 25: 339-343.

[33] Smolak L, Levine MP, Schermer F. Parental input and weight concerns among elementary school children. Int J Eat Disord 1999; 25: 263-271.

[34] Smolak L, Thompson JK. Body image in children. In: Thompson JK \& Smolak L (Eds). Body image, eating disorders and obesity in youth: Assessment, prevention and treatment. Washington DC, American Psychological Association 2001; pp. 41-66.

[35] Cuzzolaro M, San Martino L, Zardo E. La valutazione psicometrica. In: Caruso R, Manara F (Eds). I disturbi del comportamento alimentare. Angeli, Milano 1997; pp. 41-56.

[36] Childress AC, Jarrell MP, Brewerton TD. The Kids' Eating Disorders Survey (KEDS): internal consistency, component analysis, and reliability. Eat Dis J Treat Prev 1993; 1: 123-133.

[37] Childress AC, Brewerton TD, Hodges EL, Jarrell MP. The Kids' Eating Disorders Survey (KEDS): a study of middle school students. J Am Acad Child Adolesc Psychiatry 1993; 32: 843-850.

[38] Ravaldi C, Ricca V, Mezzani B, et al. CIBUS, un questionario che indaga convinzioni, pensieri e comportamenti della famiglia riguardo a cibo e corpo. Rivista di psichiatria 2006; 41: 250-259.

[39] Cairella G, Casagni L, Lamberti A, Censi L. Overweight and obesity in Italian children aged 6-11 years. Ann Ig 2008; 20: 315-27. 
[40] Favaro A, Santonastaso P. Effects of parents' psychological characteristics and eating behaviour on childhood obesity and dietary compliance. J Psychosom Res 1995; 39: 145-51.

[41] Agras S, Hammer L, McNicholas F. A prospective study of the influence of eating-disordered mothers on their children. Int $\mathrm{J}$ Eat Disord 2002; 25: 253- 62 .

[42] Cooper PJ, Whelan E, Woolgar M, Morrell J, Murray L. Association between childhood feeding problems and maternal eating disorder: role of the family environment. Br J Psychiatry 2004; 184 : 210-5.

[43] Stein A, Woolley H, Cooper SD, Fairburn CG. An observational study of mothers with eating disorders and their infants. J Child Psychol Psychiatry 1994; 35: 733- 48.

[44] Pike KM, Rodin J. Mothers, daughters, and disordered eating. J Abnorm Psychol 1991; 100: 198-204.
[45] Stein A, Woolley H, Cooper S, Winterbottom J, Fairburn CG, Cortina-Borja M. Eating habits and attitudes among 10-year-old children of mothers with eating disorders: longitudinal study. $\mathrm{Br} \mathrm{J}$ Psychiatry 2006; 189: 324-9.

[46] Leung F, Schwartzman A, Steiger H. Testing a dual-process family model in understanding the development of eating pathology: a structural equation modelling analysis. Int J Eat Disord 1996; 20: 367- 75 .

[47] Coulthard H, Blissett J, Harris G. The relationship between parental eating problems and children's feeding behavior: a selective review of the literature. Eat Behav 2004; 5: 103-15.

[48] Canals J, Sancho C, Arija MV. Influence of parent's eating attitudes on eating disorders in school adolescents. Eur Child Adolesc Psychiatry 2009; 18: 353-9.

(C) Ricca et al.; Licensee Bentham Open.

This is an open access article licensed under the terms of the Creative Commons Attribution Non-Commercial License (http://creativecommons.org/licenses/by-nc/3.0/) which permits unrestricted, non-commercial use, distribution and reproduction in any medium, provided the work is properly cited. 